\title{
A Review of Switching Strategies for Patients with Schizophrenia Comorbid with Metabolic Syndrome or Metabolic Abnormalities
}

This article was published in the following Dove Press journal:

Neuropsychiatric Disease and Treatment

\author{
Xuemei Liao',* \\ Hui $\mathrm{Ye}^{2, *}$ \\ Tianmei $\mathrm{Si}^{\mathrm{I}}$
}

'Peking University Sixth Hospital, Peking University Institute of Mental Health, NHC Key Laboratory of Mental Health (Peking University), National Clinical Research Center for Mental Disorders (Peking University Sixth Hospital), Beijing, 100191, People's Republic of China; ${ }^{2}$ Medical Department, Sanofi, Shanghai, People's Republic of China

*These authors contributed equally to this work
Correspondence: Tianmei Si

Peking University Sixth Hospital, Peking University Institute of Mental Health, NHC Key Laboratory of Mental Health (Peking University), National Clinical Research Center for Mental Disorders (Peking University Sixth Hospital), Huayuanbeilu 5I\#, Haidian District, Beijing, 100191, People's Republic of China

Tel +86 13910987793

Email si.tian-mei@I63.com

\begin{abstract}
Metabolic syndrome (MetS) in patients with schizophrenia occurs 2-3 times more frequently than in the general population. Antipsychotic medication is a primary risk factor for patients with MetS. In particular, the widely used second-generation antipsychotics can affect glucose and lipid metabolism and can induce insulin resistance and other metabolic abnormalities through various receptors. Notably, the metabolic risks of various antipsychotics may differ because of their different pharmacological affinity to MetS-related receptors. Several previous studies have shown that switching from high to low metabolic risk antipsychotics may improve patients' metabolic parameters. The current review aims to discuss the strategies for switching antipsychotic medications and the impact on metabolic abnormalities in patients with schizophrenia.
\end{abstract}

Keywords: antipsychotics, switch, metabolic syndrome

\section{Epidemiology and Risk Factors of MetS in Patients with Schizophrenia Definition and Diagnostic Criteria of MetS}

Schizophrenia is a chronic mental disorder characterized by high personal and social burden and is among the top ten medical disorders to cause disability. ${ }^{1}$ Patients with schizophrenia have significant morbidity and premature mortality, with an average life expectancy of about $80-85 \%$ that of general population. Metabolic syndrome (MetS) among patients with schizophrenia may explain part of this difference and has recently received considerable attention. The definition and diagnostic criteria of MetS vary among several different international academic organizations, causing inconsistencies in the understanding and diagnosis of MetS. Therefore, in 2005, based on the definitions of the World Health Organization (WHO) and the National Cholesterol Education Program Expert Panel Adult Treatment Panel III (NCEP-ATP-III), the International Diabetes Federation (IDF) issued a global consensus definition of MetS, namely with central obesity (defined by waist circumference) as a necessary condition plus any two of the following four factors: (1) raised triglycerides (TG); (2) reduced high-density lipoprotein (HDL-C) levels; (3) raised blood pressure; and (4) raised fasting plasma glucose. ${ }^{2}$ In recent years, there has been a trend to eliminate the necessary condition of waist circumference, which would change the definition to match the NCEP ATP-III standard that MetS can be diagnosed by meeting any three of the five conditions (adding 
central obesity as a qualifying but not sufficient condition). ${ }^{3}$ Chinese guidelines for the prevention and treatment of type 2 diabetes have led to a new definition of MetS based on characteristics of the Chinese population, which differs from international standards primarily in that they do not regard abdominal obesity (that is, central obesity) as a necessary condition for diagnosis. ${ }^{4}$

\section{Prevalence of MetS in Patients with Schizophrenia}

Previous studies have demonstrated that the risk of MetS in patients with schizophrenia is two to three times higher than that of the general population. ${ }^{5-7}$ A systematic review and meta-analysis of 126 studies (including data on more than 20,000 patients) has shown that the average prevalence of MetS in patients with schizophrenia was 32.5\%. ${ }^{8}$ Similar results were demonstrated in another meta-analysis, with a prevalence rate of $33.4 \%{ }^{9}$ Studies from some countries in Europe, America, and Asia have shown a prevalence rate of $22.8-40.9 \%$. ${ }^{6,10-14}$ Several surveys and studies in China between 2006 and 2017 have demonstrated a similar prevalence of MetS in Chinese outpatients and inpatients with schizophrenia, between 25.4 and $43.9 \% .^{15-19}$

\section{Effects of MetS on Patients with Schizophrenia}

MetS is a major challenge for patients with schizophrenia, not only because of its direct impact on the increased incidence and mortality of cardiovascular disease but also because of the influence on the outcome of mental illness. First, MetS can increase the risk of cardiovascular disease and, subsequently, death, ${ }^{20}$ cardiovascular disease is, indeed, the leading cause of death in patients with schizophrenia. ${ }^{21}$ The risk of death from cardiovascular disease in patients with schizophrenia who are aged 16-50 years is over three times that of the general population. ${ }^{22}$ A multi-center cross-sectional study of 1452 outpatients with schizophrenia demonstrated that within ten years, those with MetS had a significantly higher risk of coronary heart disease and cardiovascular death and comprised a significantly higher proportion of extremely high to high risk of coronary heart disease and extremely high to high risk of cardiovascular death compared to patients without MetS $(p<0.001)$. Second, patients with MetS have demonstrated significantly higher total positive and negative syndrome scale (PANSS) scores, positive symptom scores, and negative symptom scores than those without MetS, suggesting more serious psychotic symptoms. ${ }^{23}$ Patients with MetS are more likely to have reduced medication compliance and are at an increased risk of mental illness recurrence. ${ }^{24,25}$ The FondaMental Academic Centers of Expertise for Schizophrenia (FACE-SZ) cohort study demonstrated that MetS is a strong predictor of a one year recurrence rate of schizophrenia, but is unrelated to the severity of the disease, insight into the disease, or treatment (including drug compliance). The risk of recurrence within 12 months in patients with MetS is three times that in patients without MetS (OR $=3.0 ; 95 \%$ CI: $1.1,8.4) .{ }^{25}$ In addition, MetS may impair the cognitive function of patients with schizophrenia. $^{26}$

\section{Etiological Risk Factors for MetS in Patients with Schizophrenia}

Despite the controversy, increasing evidence suggests that schizophrenia itself is an independent risk factor for MetS. ${ }^{27}$ In patients with first-episode schizophrenia, there is already an impairment of glucose tolerance and insulin resistance and their glucose, insulin, and cortisol levels are higher than in the general population. ${ }^{28}$ Even in patients with psychotic symptoms who have not yet been diagnosed with schizophrenia, the prevalence of a diagnosis of MetS is higher than in the general population, including symptoms such as increased blood pressure, increased waist circumference, and rapid glucose increase, among others. ${ }^{29}$ Studies have found that schizophrenia has genetic factors that are susceptible to MetS; there are overlaps between schizophrenia and MetS with some pathogenic genes. For example, the homozygosity of the methylenetetrahydrofolate reductase (MTHFR) gene C677Thr is associated with an increased risk of schizophrenia and coronary heart disease and the adrenergic $\alpha 1 \mathrm{~A}$ receptor (ADRA1A) gene Arg347 allele is associated with the severity of MetS in patients with schizophrenia. ${ }^{30-32}$ The pathophysiological process of metabolic abnormalities in schizophrenia may be related to hypothalamic-pituitaryadrenal (HPA) axis disorders, insulin resistance, and increased levels of inflammatory factors. ${ }^{27,32,33}$ In addition, demographic and behavioral susceptibility factors are present in patients with schizophrenia, such as age, gender, course of disease, family history, and ethnic factors, which may also be susceptibility factors for MetS. ${ }^{8,15,33,34}$ In particular, multiple studies have confirmed the influence 
of age and disease course and the prevalence of MetS increases with the course of disease and with age. ${ }^{6,8,9} \mathrm{In}$ addition, schizophrenic patients' sedentary lifestyle, lack of regular exercise, poor diet, substance abuse, smoking, and other deleterious health behaviors may increase the risk of MetS; these behaviors may also be related to the negative symptoms of schizophrenia and have a susceptibility to stress. ${ }^{5}$

\section{Antipsychotics as a Risk Factor for MetS}

In addition to disease factors, antipsychotics are also an important risk factor for MetS. A meta-analysis that included a total of 26 studies of patients with first-episode schizophrenia, 19 studies of patients with untreated schizophrenia, and 78 studies of patients with schizophrenia treated with antipsychotics demonstrated that the incidence of MetS increased significantly after patients received antipsychotics and the risk of increased waist circumference, hypertension, elevated triglycerides, decreased HDL-C, and diabetes also increased significantly. ${ }^{8}$

Antipsychotics affect glucose, lipid metabolism, and weight gain through multiple receptor pathways, thereby increasing the risk of MetS in patients with schizophrenia. ${ }^{33,35,36}$ For example, antipsychotics can antagonize receptors such as 5-HT $\left(5-\mathrm{HT}_{2 \mathrm{C}}\right)$ and histamine (H1), which can lead to an increase in appetite and weight gain and can antagonize central and peripheral muscarinic receptors (M3) and directly act on pancreatic islet $\beta$ cells to affect insulin secretion and glucose metabolism. ${ }^{33,36} \mathrm{H} 1$ receptors are localized in the hunger and satiety centers held in the hypothalamus and are responsible for hyperphagia. ${ }^{36,37}$ The occurrence of diabetes may, then, be related to the antagonism of M3 receptors, which are located in the $\beta$ cells of the pancreas and can regulate insulin release and change the blood glucose metabolism. M3 receptor antagonism can affect glucose metabolism, leading to diabetes, ketoacidosis, and hypertonic syndrome, among other disorders. ${ }^{36,37}$ In addition, H1, M1, and adrenergic $\alpha 1$ receptor antagonism may have a sedative effect, leading to a sedentary lifestyle and obesity in patients with schizophrenia. ${ }^{32,36}$ The correlation between $\mathrm{H} 1,5-\mathrm{HT}_{2 \mathrm{C}}$, and $\mathrm{M} 3$ receptor antagonism (based on receptor occupancy) with weight gain and diabetes risk has also been demonstrated in some model analyses and pharmacoepidemiology-pharmacodynamic (PE-PD) research methods, particularly $\mathrm{H} 1$ and $5-\mathrm{HT}_{2 \mathrm{C}}$ antagonism. ${ }^{38-40}$
Different antipsychotics share different pharmacological affinity to $5-\mathrm{HT}_{2 \mathrm{C}}, \mathrm{H} 1$, and $\mathrm{M} 3$ receptors. Among the first-generation antipsychotics, Chlorpromazine has the highest antagonistic effect on MetS-related receptors, particularly $5-\mathrm{HT}_{2 \mathrm{C}}$ and $\mathrm{H} 1$ receptors, while Sulpiride and Haloperidol have no or very poor antagonistic effects. In contrast, the pharmacological effects of second-generation antipsychotics (SGAs) are more complicated and may have effects on a variety of MetS-related receptors. Based on the receptor occupancy rate, Clozapine has a high antagonistic effect on 5- $\mathrm{HT}_{2 \mathrm{C}}, \mathrm{H1}$, and $\mathrm{M} 3$ receptors, followed by Olanzapine, Quetiapine, and Asenapine. Lurasidone, Aripiprazole, and Ziprasidone have weak antagonism, while Amisulpride has no antagonism to these receptors. ${ }^{38-40}$ Some newer SGAs, such as Brexpiprazole and Cariprazine, also seem to have weak or no antagonism on MetS-related receptors. ${ }^{36}$

The overall risk of MetS caused by various antipsychotics is consistent with their pharmacological properties. Among them, Clozapine and Olanzapine have the highest risks for blood glucose, blood lipids, weight gain, and MetS, followed by Quetiapine, Risperidone, and Paliperidone, while Lurasidone, Ziprasidone, Amisulpride, Aripiprazole, and newer antipsychotics like Brexpiprazole and Cariprazine have the lowest risks. Among the first-generation antipsychotics, Chlorpromazine, with a high affinity for $\mathrm{H} 1$ and 5$\mathrm{HT}_{2 \mathrm{C}}$ receptors, is associated with a higher risk of weight gain, dyslipidemia, and abnormal blood glucose, while Haloperidol and Sulpiride have a relative lower risk. ${ }^{40-44}$ Table 1 shows the relative MetS risks of antipsychotics based on an integrated analysis of the different international guidelines and meta-analyses.

Apart from antipsychotics, mood stabilizers, such as lithium and antiepileptics, may also contribute towards increase in metabolic risks. ${ }^{45}$ As mood stabilizers are often used as add-on therapy for patients with schizophrenia in the clinical practice, ${ }^{46}$ combining antipsychotics with mood stabilizers seem to lead to greater metabolic risks.

\section{General Management of MetS in Patients with Schizophrenia}

Schizophrenia and MetS are chronic and, therefore, longterm management should be considered. First, paying attention to the baseline evaluation (prior to treatment), weighing the advantages and disadvantages, and carefully choosing antipsychotics with better efficacy and lower MetS risks according to the patient's condition, symptom 
Table I Relative MetS Risk of Commonly Used Antipsychotics

\begin{tabular}{|c|c|c|c|c|c|c|c|}
\hline \multirow{2}{*}{\multicolumn{2}{|c|}{ Drug }} & \multicolumn{3}{|c|}{$\begin{array}{l}\text { Receptor Antagonism (Based } \\
\text { on Receptor Occupancy) }\end{array}$} & \multirow[t]{2}{*}{ MetS Risk - Lipids } & \multirow[t]{2}{*}{ MetS Risk - Glucose } & \multirow[t]{2}{*}{ MetS Risk - Body Weight } \\
\hline & & $5-\mathrm{HT}_{2 \mathrm{C}}$ & HI & M3 & & & \\
\hline \multirow[t]{3}{*}{ FGAs } & Haloperidol & - & - & - & Low & Medium & Low \\
\hline & Sulpiride & - & - & Low & Low & Low & Low \\
\hline & Chlorpromazine & High & High & Low & High & High & High \\
\hline \multirow[t]{13}{*}{ SGAs } & Clozapine & High & High & High & High & High & High \\
\hline & Olanzapine & High & High & Low & High & High & High \\
\hline & Risperidone & Medium & Medium & - & Medium & Medium & Medium \\
\hline & Paliperidone & Medium & Low & - & Medium & Medium & Medium \\
\hline & Quetiapine & Low & High & Low & Medium & Medium & Medium \\
\hline & Ziprasidone & Medium & Low & - & Low & Low & Low \\
\hline & Aripiprazole & Low & Low & - & Low & Low & Low \\
\hline & Amisulpride & - & - & - & Low & Low & Low \\
\hline & Asenapine & High & High & - & Medium & Medium & Medium \\
\hline & Lurasidone & Medium & Low & - & Low & Low & Low \\
\hline & Serindole & High & - & - & Low & Low & Medium \\
\hline & Cariprazine & Low & Low & - & Low & Medium & Low \\
\hline & Brexpiprazole & Low & Low & - & Low & Low & Low \\
\hline
\end{tabular}

Notes: Receptor antagonism: Results are excerpted from Aringhieri et al, ${ }^{38}$ Montastruc et al, ${ }^{40}$ Stahl et al $^{36}$. Relative receptor antagonism ranking is based on receptor occupancy; “-" refers to no receptor occupancy. MetS risk of lipids/glucose/body weight: Relative MetS risk ranking is based on multiple international guidelines and metaanalyses, including Galletly et al, ${ }^{42}$ Hasan et al, ${ }^{43}$ Zhao et al. ${ }^{44}$

Abbreviations: FGAs, first-generation antipsychotics; SGAs, second-generation antipsychotics; MetS, metabolic syndrome.

characteristics, duration, number of episodes, previous treatment, and adverse drug reactions, among other symptoms is important. Immediately after treatment initiation, metabolic parameters should be continuously monitored and the trend of changes in the metabolic parameters should be observed frequently to detect and intervene on metabolic abnormalities as soon as possible, particularly body mass index (BMI), waist circumference, blood pressure, fasting blood glucose, glycosylated hemoglobin, fasting triglycerides, HDL-C, and low-density lipoprotein cholesterol (LDL-C), and any other relevant metabolic parameters. ${ }^{42,43}$ Various treatment guidelines have different requirements for the monitoring frequency of metabolic parameters, but they all require that body weight (i.e. $\mathrm{BMI})$ is monitored the most frequently.

Abnormal changes in metabolic parameters within a short period of time may indicate long-term metabolic problems. Early intervention is required if changes are found during the monitoring of metabolic parameters. For example, after treatment with antipsychotics for one month, an increase in total cholesterol, LDL-C, TG, and non-HDL-C by 5\% and a decrease in HDL-C by $5 \%$ can predict abnormal changes in blood lipids after three months. ${ }^{47}$ Another study of adolescents also demonstrated that if weight gain exceeds the baseline by $4 \%$ after treatment with atypical antipsychotics for one month, there is a higher risk of $15 \%$ weight gain after three months of treatment. ${ }^{48}$ Therefore, guidelines often recommend that when weight gain exceeds $7 \%$, sufficient attention should be given and non-pharmacological intervention should be started and when weight gain exceeds $10 \%$, the existing treatment plan should be evaluated. To prevent further weight gain, it is essential to encourage weight loss and to switch medications if necessary. ${ }^{43,44}$

Common management methods of MetS include lifestyle intervention, switching to antipsychotics with a lower metabolic risk, and combining treatment with other drugs. Common lifestyle interventions include educational, dietary, and exercise programs. However, the effect of lifestyle intervention is still controversial, particularly in long-term treatment. A meta-analysis of 41 randomized controlled trials (RCT) showed that, compared with controls, the lifestyle intervention group significantly reduced their BMI by $0.63 \mathrm{~kg} / \mathrm{m}^{2}(p=0.002)$, but after an average follow-up of 32 weeks, it was found that although the effect size of the remaining 17 RCTs was still adequate, it was no longer statistically significant. Another randomized, parallel controlled, superiority multi-center clinical trial showed that, in patients with psychiatric disorder 
spectrum and abdominal obesity, life guidance or reasonable care was not superior to conventional treatment to reduce cardiovascular risk. ${ }^{49,50}$ It is generally believed that lifestyle interventions from the beginning of antipsychotic treatment as a preventive strategy may reduce metabolic risks such as obesity in patients with schizophrenia and provide more benefits. ${ }^{51,52}$

Multiple studies have suggested that combination treatments can help control weight and improve metabolic parameters, including Metformin, Aripiprazole, Amantadine, Topiramate, Orlistat, Melatonin, Reboxetine, Zonisamide, Naltrexone, Bupropion, and Betahistine, among others. ${ }^{53-62}$ A combination of Aripiprazole or other antipsychotics with a low metabolic risk may be a successful strategy. A meta-analysis and systematic review showed that, among patients with schizophrenia or schizoaffective disorder treated with Olanzapine or Clozapine, combining their current treatment with Aripiprazole at 5-15 mg per day for 8-16 weeks could decrease a patient's weight by $2.13 \mathrm{~kg}(95 \% \mathrm{CI}:-2.87,-1.39 \mathrm{~kg}) .{ }^{54}$ Another common combination strategy is the addition of hypoglycemic drugs. In recent years, several studies have suggested that a combined Metformin at 500-2000 mg per day can significantly improve metabolic parameters such as weight gain caused by antipsychotics. ${ }^{63-66} \mathrm{An}$ analysis of ten randomized controlled studies showed that combining Metformin with current treatment improved the metabolic abnormalities caused by antipsychotics and weight loss was significantly different compared with placebo $(-3.17 \mathrm{~kg} ; 95 \% \mathrm{CI}:-4.44,-1.90 \mathrm{~kg}){ }^{54}$ Although combined drugs may be effective for MetS, they also involve drug interactions and adverse effects caused by multi-drug therapy. For example, common adverse reactions of Metformin include nausea, abdominal distension, and diarrhea. ${ }^{67}$

\section{Summary of Studies on}

\section{Antipsychotics Switching Strategy for MetS in Patients with Schizophrenia}

Another common management mode for MetS is to switch to an antipsychotic with lower metabolic risks, such as Aripiprazole, Amisulpride, or Ziprasidone, to improve metabolic parameters. Drug switching may improve MetS in patients with schizophrenia, but it also involves the risk of worsening and/or recurrence of psychotic symptoms. Therefore, issues such as poor control of psychotic symptoms, adverse reactions, and the possibility of weight gain after switching to other drugs should be considered before switching to weigh the risks and benefits. Meanwhile, patients and caregivers must be informed of the possible consequences of switching drugs and corresponding treatment plans must be prepared. ${ }^{68}$

Currently, most studies focus on Aripiprazole, Amisulpride, or Ziprasidone when examining the strategy of switching to antipsychotics with lower metabolic risks, with a few focusing on Quetiapine or Lurasidone (Table 2). Most of the studies are multi-center, randomized controlled, open studies, but there are some are prospective, double-blind, and extended studies. The study population includes patients with psychosis spectrum disorder, primarily including schizophrenia, schizoaffective disorder, and, more infrequently, bipolar disorder, whose condition is stable and is treated with a stable dose of antipsychotics. In most cases, the switch occurs from SGAs with a high metabolic risk, such as Olanzapine, Clozapine, or Risperidone, and less frequently from firstgeneration antipsychotics such as Haloperidol, to drugs with a lower metabolic risk, such as Aripiprazole, Amisulpride, Ziprasidone, Quetiapine, or Lurasidone. Cross-tapering is the method most frequently adopted. The switch usually occurs due to the patient's significant weight gain, elevated blood lipids, and other metabolic abnormalities, or a clear diagnosis of MetS, resulting in poor treatment compliance. The observation period of the studies ranges from 6 to 52 weeks, of which a duration of 8,12 , or 24 weeks is the most common. The outcome of switching is usually subject to a comprehensive evaluation of metabolic parameters (including weight, BMI, waist circumference, blood pressure, blood lipid levels, rapid blood glucose, and insulin), efficacy parameters (commonly used include PANSS, clinical global impressionsseverity (CGI-S), brief psychiatric rating scale (BPRS), and quality of life), and treatment interruption rates and adverse drug reactions.

\section{Amisulpride (Two Primary Studies)}

The existing studies show that a switch to Amisulpride to address treatment failure, intolerance, or excessive BMI due to the use of SGAs, including Olanzapine and Risperidone, among others, can significantly improve metabolic parameters such as body weight and BMI within 4-6 weeks and has demonstrated effects on other parameters such as blood glucose, blood lipids (TG, total cholesterol, HDL-C), blood pressure, and waist circumference at 12 months. ${ }^{69,70}$ Lin et al further demonstrated that, 


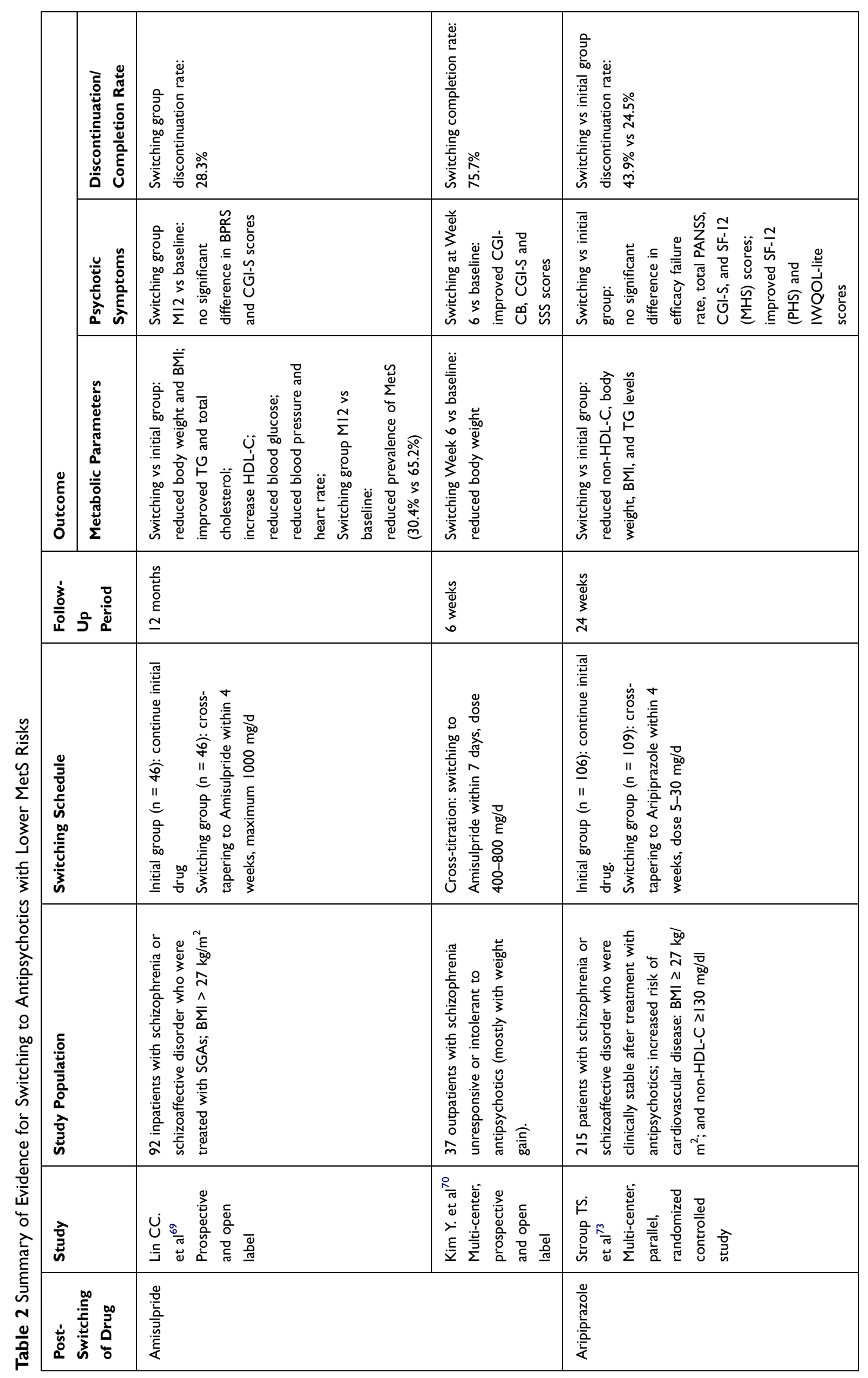




\begin{tabular}{|c|c|c|}
\hline 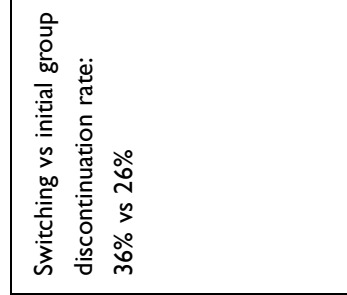 & 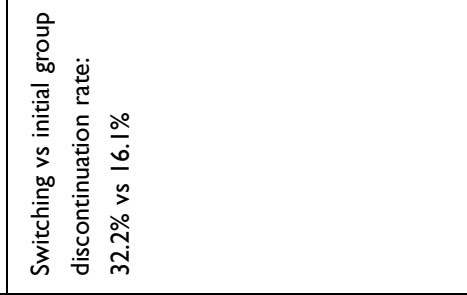 & 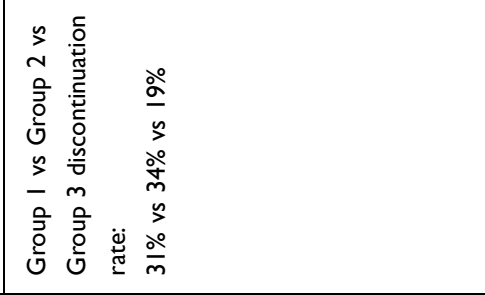 \\
\hline 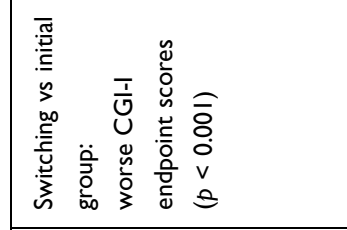 & 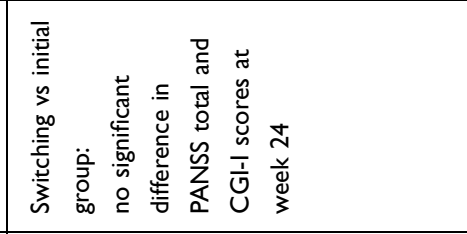 & 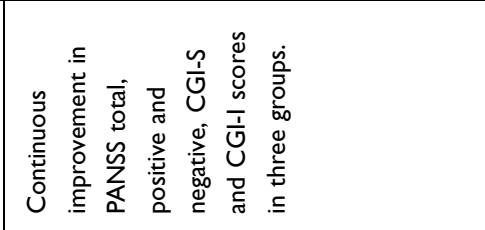 \\
\hline 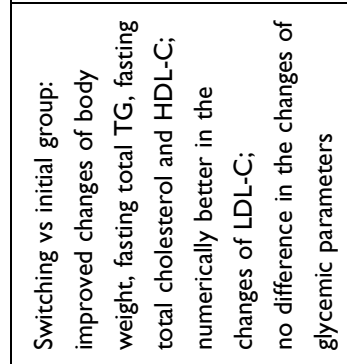 & 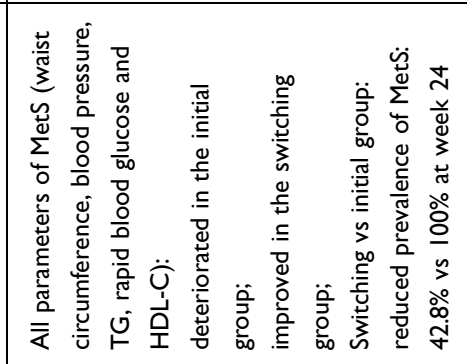 & 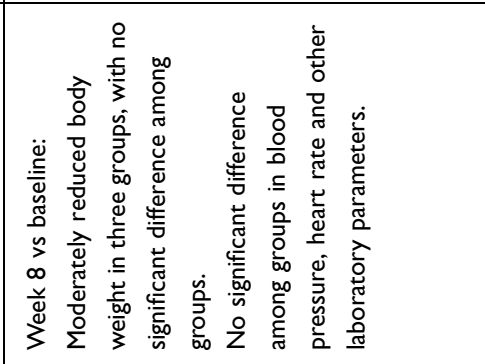 \\
\hline $\begin{array}{l}\frac{y}{\underline{g}} \\
\underline{\underline{\phi}} \\
\underline{0}\end{array}$ & 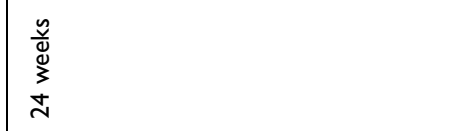 & 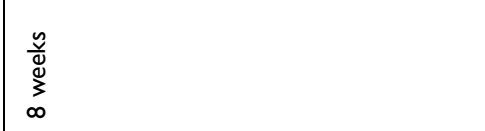 \\
\hline 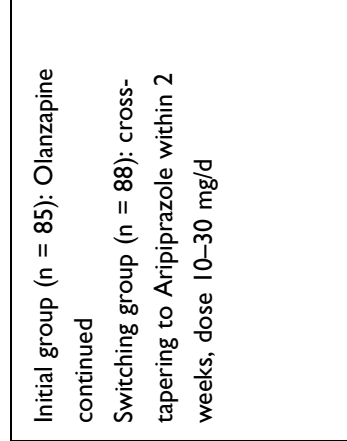 & 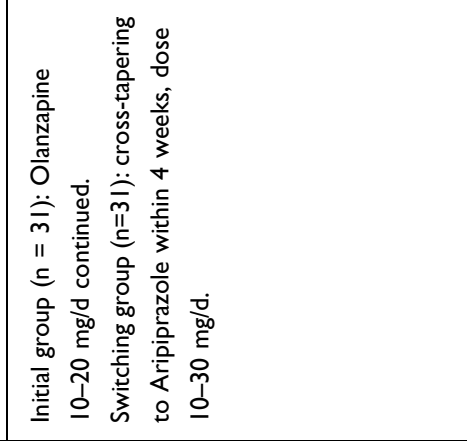 & 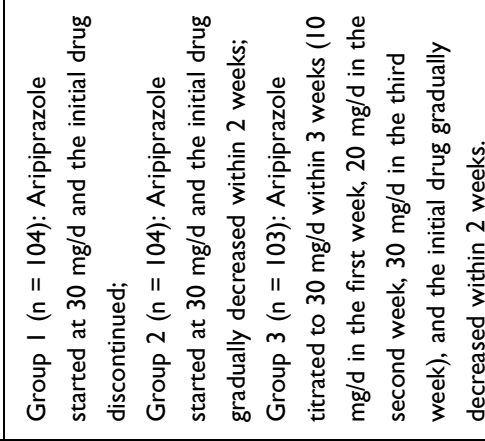 \\
\hline 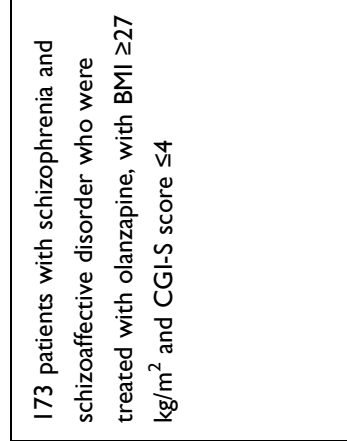 & 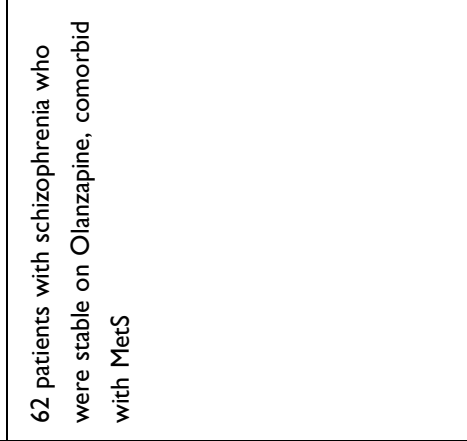 & 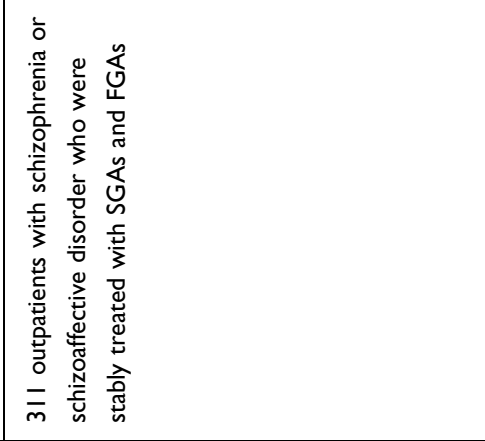 \\
\hline 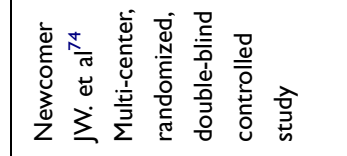 & 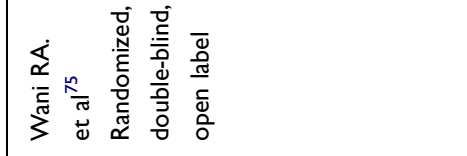 & 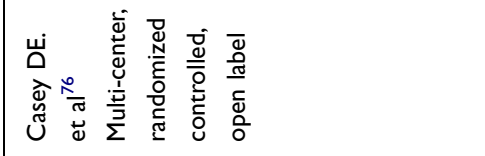 \\
\hline
\end{tabular}




\begin{tabular}{|c|c|c|c|}
\hline 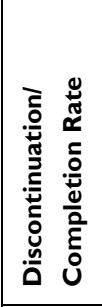 & 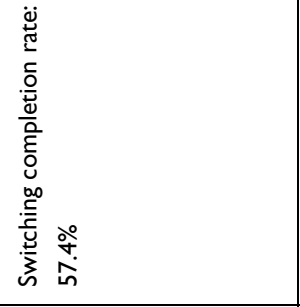 & 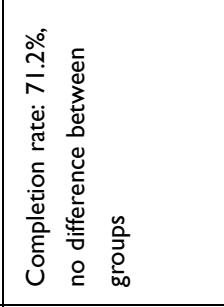 & 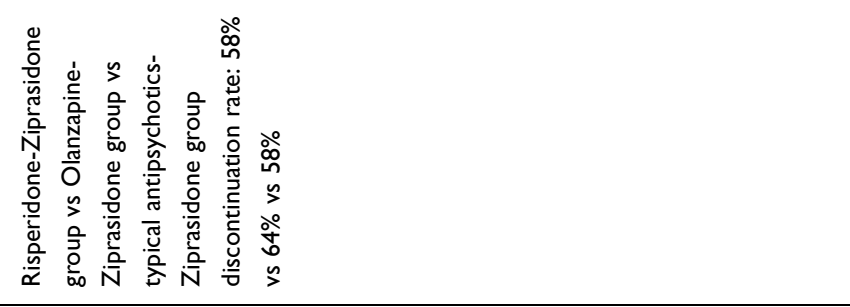 \\
\hline 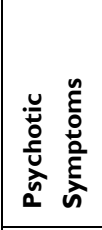 & 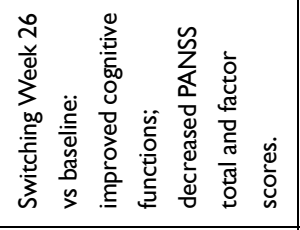 & 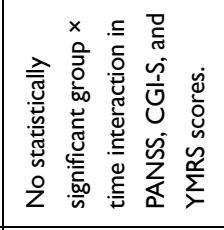 & 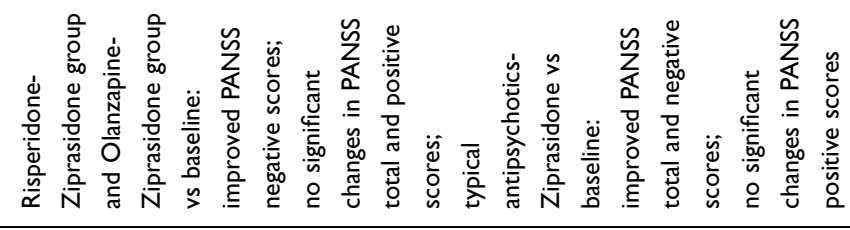 \\
\hline 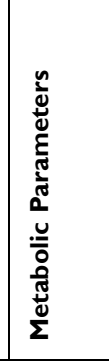 & 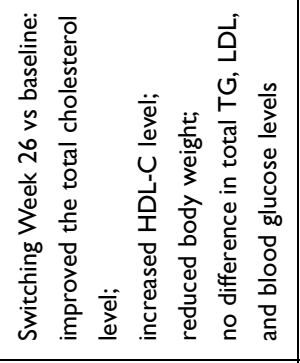 & 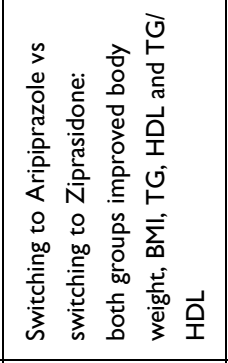 & 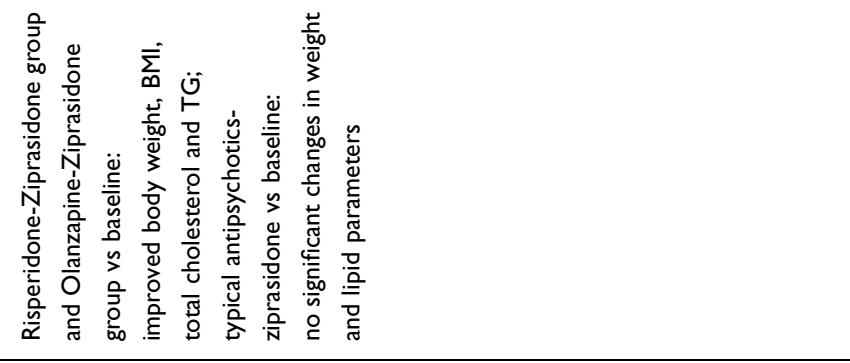 \\
\hline 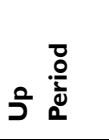 & 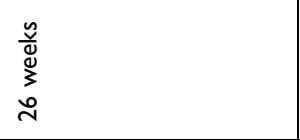 & 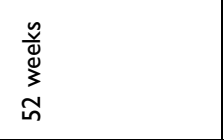 & 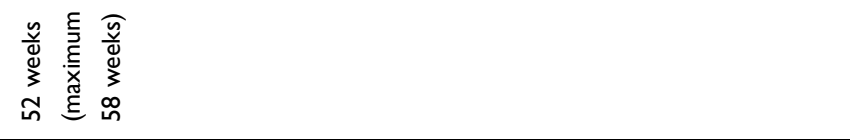 \\
\hline & 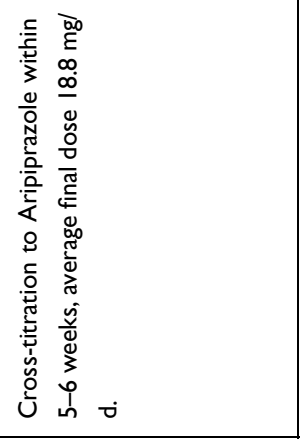 & 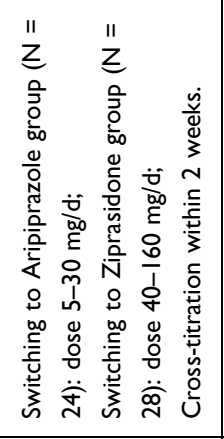 & 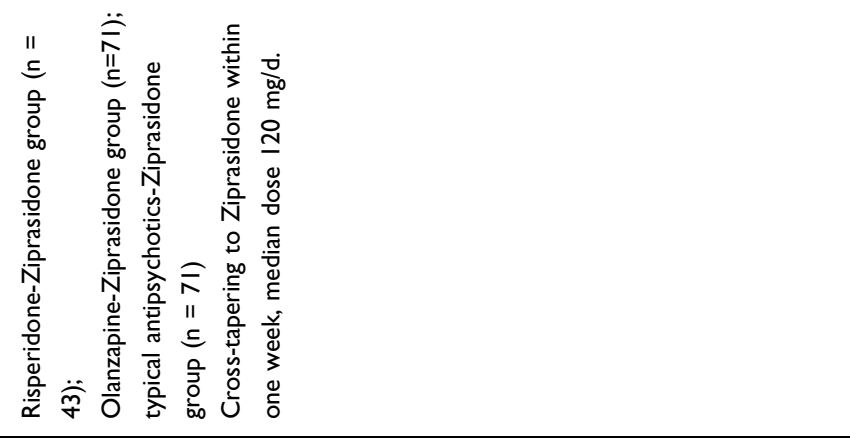 \\
\hline & 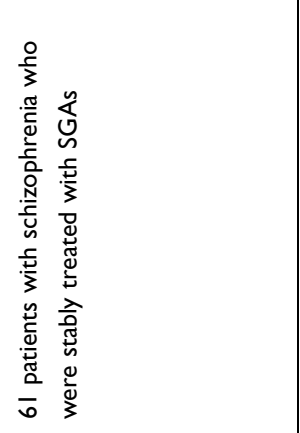 & 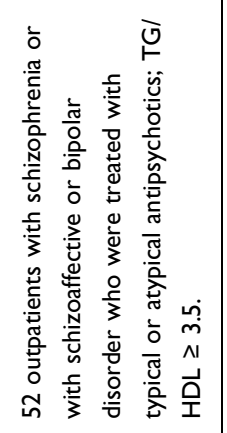 & 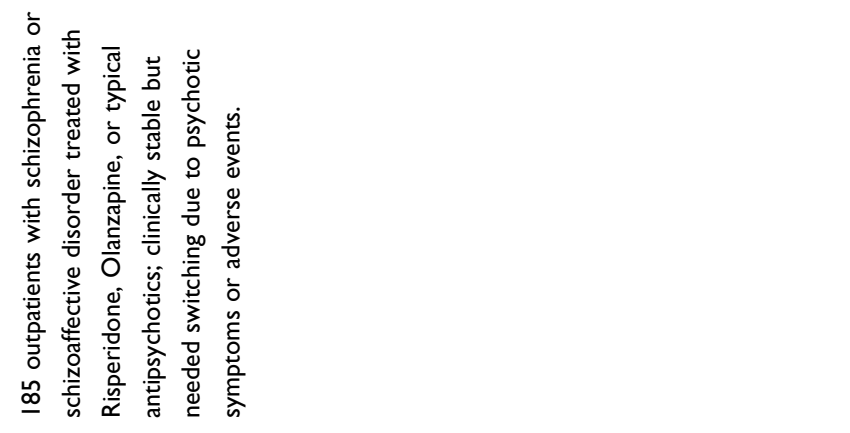 \\
\hline & 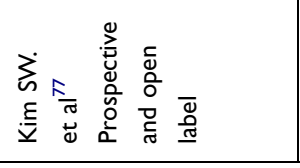 & 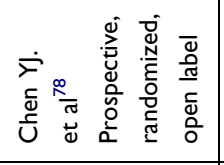 & 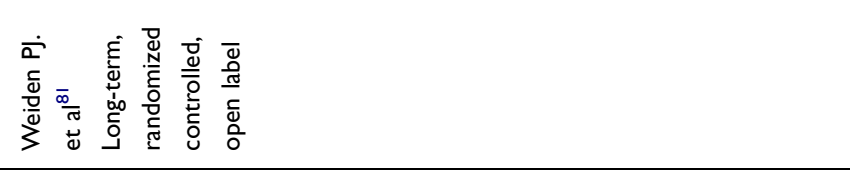 \\
\hline 总 & & & 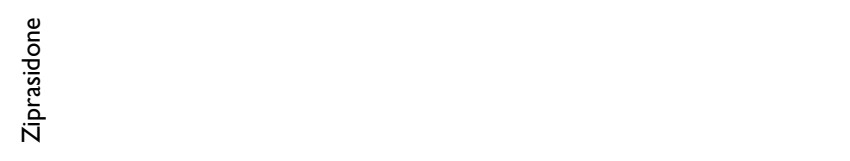 \\
\hline
\end{tabular}




\begin{tabular}{|c|c|c|}
\hline 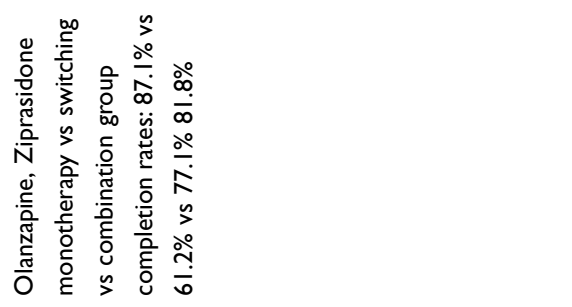 & 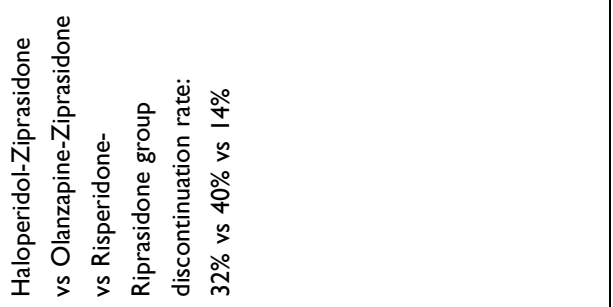 & 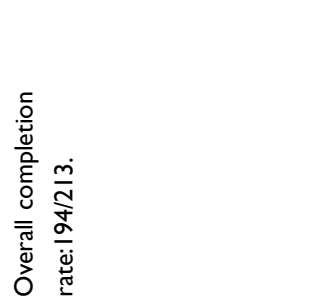 \\
\hline 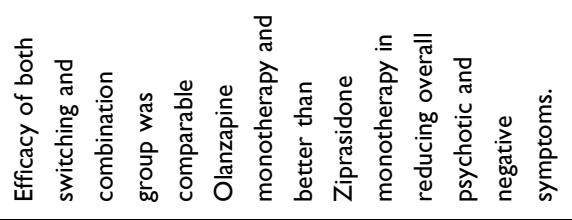 & 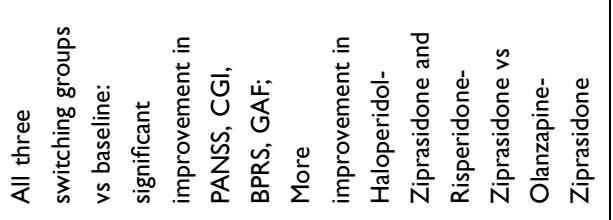 & 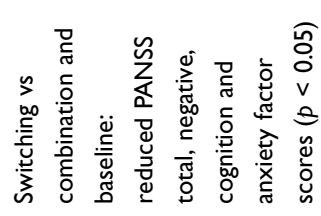 \\
\hline 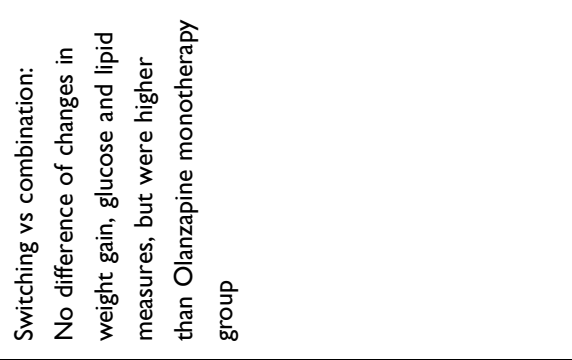 & 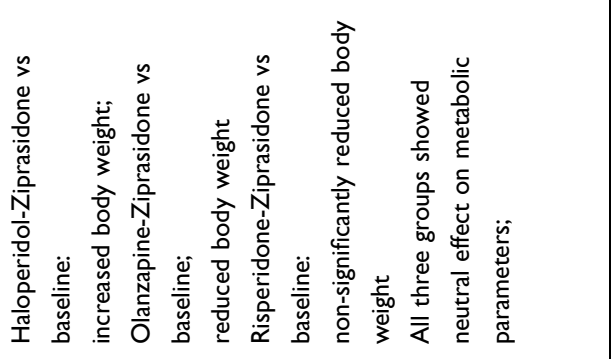 & 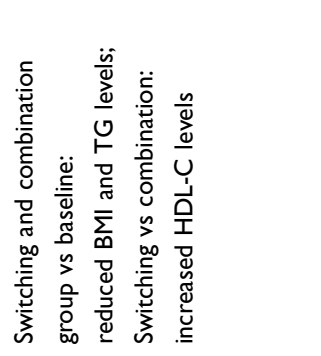 \\
\hline 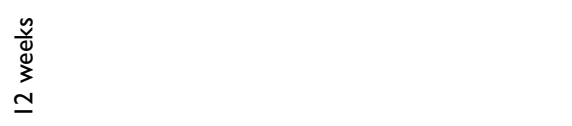 & 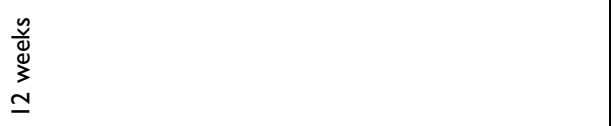 & 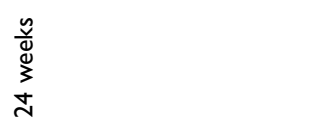 \\
\hline 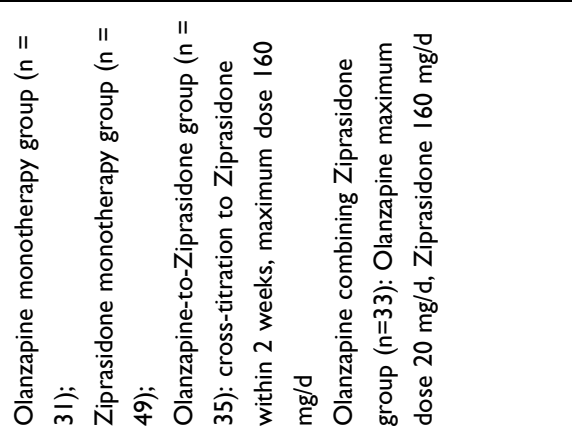 & 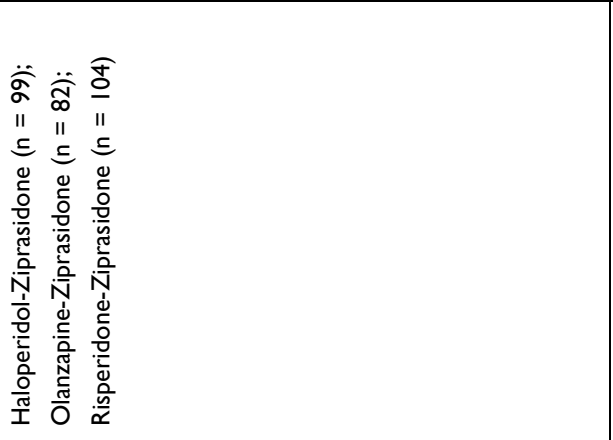 & 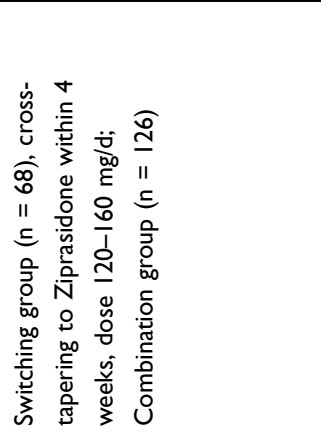 \\
\hline 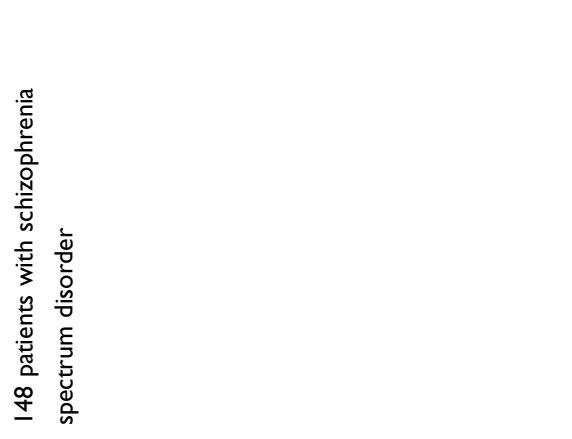 & 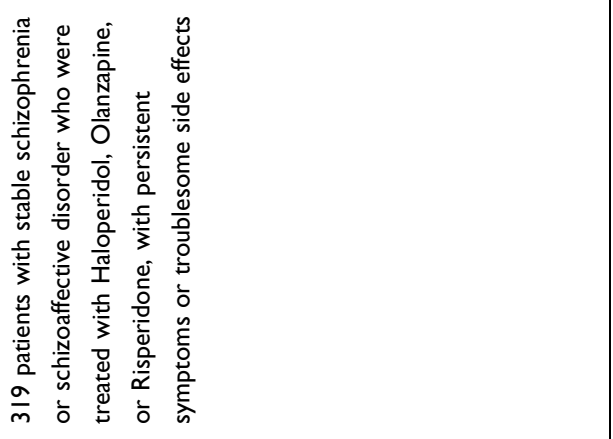 & 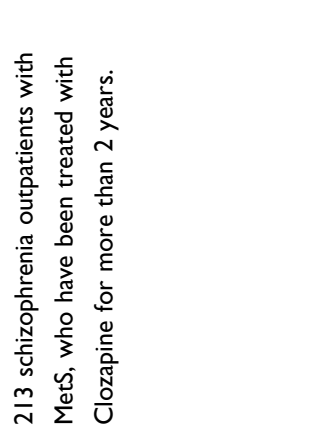 \\
\hline 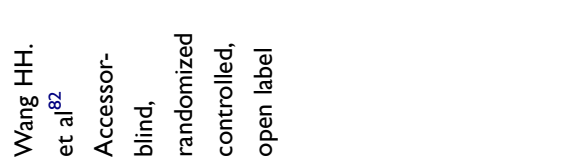 & 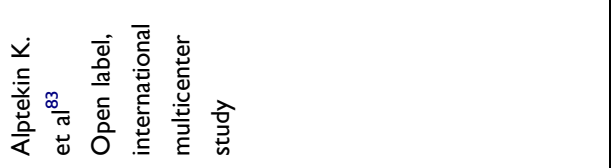 & 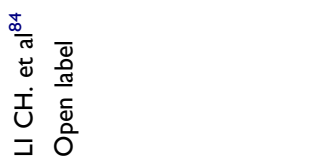 \\
\hline
\end{tabular}




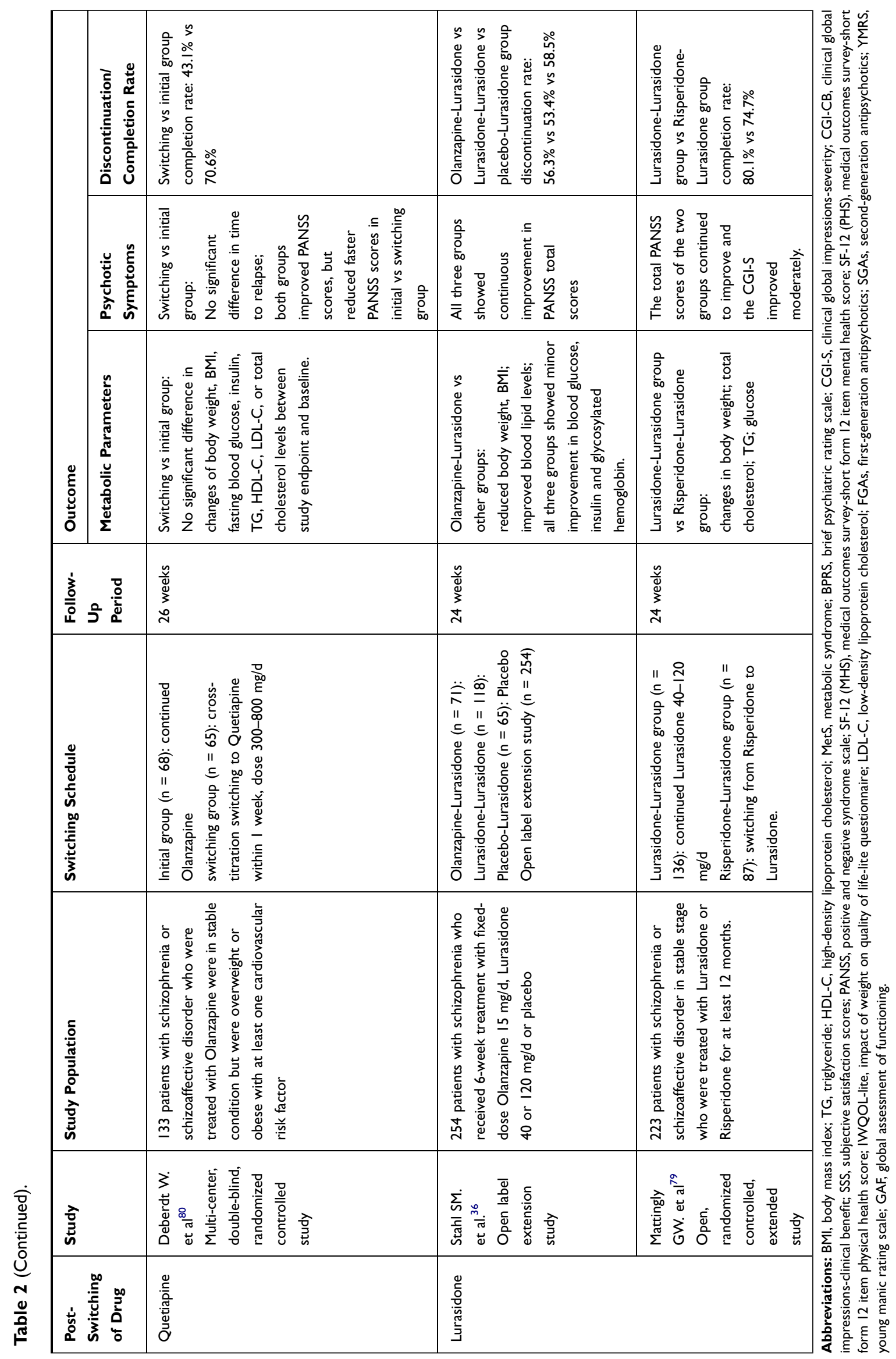


compared with $\sim$ done drugs (Risperidone and Ziprasidone), following a switch to Amisulpride from previously used $\sim$ pine drugs (Olanzapine, Quetiapine, and Zotepine), body weight, BMI, and other metabolic parameters decrease more significantly. ${ }^{69}$ Additionally, studies show that switching to Amisulpride causes improvement, or at least no deterioration, in psychotic symptoms, with improvement in CGI-S $(-0.6 \pm 0.9, \mathrm{p}=$ 0.001 , week 6 vs baseline) and clinical global impressions-clinical benefits (CGI-CB) scores $(-1.7 \pm 1.0$, $\mathrm{p}<0.0001$, week 6 vs baseline $)^{65}$ or no significant difference in the BPRS score $(-0.1 \pm 8.1, \mathrm{p}=0.913$, month 12 vs baseline). ${ }^{64}$ The safety assessment also shows good tolerability, minor side effects, and a completion rate of greater than $70 \%$ after switching. The treatment discontinuation rate after switching was $24.3 \%-28.3 \%$, with withdrawals due to deterioration accounting for about half of the discontinuation rate. Furthermore, some clinical observational studies have demonstrated that the primary reason for switching from Olanzapine to Amisulpride is weight gain $(72.6 \%)$ or the expectation of less weight gain with Amisulpride $(84.1 \%){ }^{71}$ Switching from typical antipsychotics to Amisulpride may improve patient compliance, including in patients who fail to comply with their previous treatment. ${ }^{72}$

\section{Aripiprazole (Six Studies)}

Aripiprazole studies have a follow-up period of 8, 12, 24, 26, or 52 weeks and most involve a switch from Olanzapine or Risperidone to Aripiprazole. ${ }^{73-78}$ The results of the studies demonstrate that, when maintaining the original drug regimen, metabolic parameters such as waist circumference, blood pressure, TG, rapid blood glucose, and HDL-C continue to deteriorate, but almost all metabolic parameters improve after switching to Aripiprazole, with improvement in weight and blood lipids seen in the 4 th week and continuing through weeks 16, 24, and even 52. Efficacy remains stable or improves after switching and the quality of life related to weight also improves significantly. After switching, the side effects are not obvious, and the tolerance is often good. However, the drop-out rate of the switching group was high, with most studies demonstrating above $30 \%$ and the discontinuation rate could reach $77.8 \%$ when the initial dose was above $15 \mathrm{mg}$ per day. ${ }^{77}$

\section{Lurasidone (Two Studies)}

Lurasidone has been on the market for a short time and, to date, only two studies exist on switching from Olanzapine or Risperidone to Lurasidone, both of which have a follow-up of six months. ${ }^{36,79}$ The results demonstrate that switching from Olanzapine to Lurasidone significantly reduces body weight and BMI and improves blood lipids after six months of treatment, while blood glucose, insulin, and glycosylated hemoglobin improve less so. The efficacy continues to improve, with a good safety profile. After switching from Risperidone to Lurasidone, body weight, BMI, waist circumference, TG, and blood glucose decrease slightly, but total cholesterol increases and glycosylated hemoglobin remains unchanged. The efficacy continues to improve, side effects are not significantly different, and safety is satisfactory. ${ }^{36,79}$ However, the treatment discontinuation rate is relatively high, ranging from $25.3 \%$ to $58.5 \%$.

\section{Quetiapine (One Study)}

There are limited studies on switching to Quetiapine. One multi-center, double-blind, randomized controlled study explored the efficacy and metabolism of the effect of switching from Olanzapine to Quetiapine with a 24-week follow-up period. The results show that, compared with baseline, there was no significant change in body weight, BMI, fasting blood glucose, insulin, TG, HDL-C, LDL-C, or total cholesterol between the Olanzapine group and the Quetiapine group at the end of week $26 .{ }^{80}$ Although there was no difference in the duration of the stable phase or the time to recurrence between the two groups, the total PANSS score of the Olanzapine group improved faster and the PANSS score of the Quetiapine group was significantly higher than the Olanzapine group. The treatment discontinuation rate and the discontinuation rate due to poor efficacy or psychiatric adverse events in the Olanzapine group were also higher than those in the Quetiapine group.

\section{Ziprasidone (Five Studies)}

Studies on Ziprasidone had a follow-up period of 12, 24, or 52 weeks, which included a switch from Olanzapine, Clozapine, Risperidone, or the typical antipsychotic Haloperidol to Ziprasidone. ${ }^{81-84}$ The results showed that switching from Olanzapine to Ziprasidone is related to a significant improvement in body weight and continued improvement in other metabolic parameters such as waist circumference, systolic blood pressure, BMI, TG, and blood glucose. The efficacy parameters showed no difference when compared with baseline. The existing studies also suggested that the type of drug that the subject started 
on reflects a difference on the impact on metabolic parameters and psychotic symptoms when switching to Ziprasidone. For example, bodyweight improved when switching from Olanzapine, with no difference when switching from Risperidone and even resulted in weight gain when switching from Haloperidol. Furthermore, efficacy improvements were more significant when switching from Risperidone and Haloperidol. ${ }^{83}$ Study results also showed that weight, BMI, and TG of patients consistently improved during the 52-week follow-up when switching from Olanzapine or Risperidone to Ziprasidone, but nothing improved significantly except total cholesterol and efficacy when switching from the first-generation antipsychotics. ${ }^{81}$

Chen et al also compared the effects of switching to different drugs such as Ziprasidone and Aripiprazole on metabolism and efficacy. The results showed that during the 52-week follow-up, switching to two drugs may improve metabolic parameters with no differences between the groups. Ziprasidone tends to have superior effects of improving body weight and BMI, lowering total cholesterol, and increasing HDL-C, while Aripiprazole tends to have superior effects of lowering TG/HDL and HBA1c. ${ }^{78}$ Another single-blind (accessor-blind) randomized open-label study compared the efficacy and tolerability of switching from Olanzapine to Ziprasidone and their combination. The results demonstrated that, compared with Olanzapine alone, both switching to Ziprasidone and adding Ziprasidone to Olanzapine can significantly improve metabolic parameters such as body weight, blood glucose, and blood lipids, with no significant difference between the Ziprasidone alone and combination groups. ${ }^{82}$ The treatment discontinuation rate after switching varies widely, from the $8.9 \%$ to $64 \%$, which may be related to the initial drug. For example, the dropout rate of switching from Olanzapine to Ziprasidone was $40 \%$, which was higher than switching from Haloperidol $(32 \%)$ or Risperidone (14\%). The primary reason for dropout was the side effects. ${ }^{83}$

\section{Brexpiprazole and Cariprazine}

Newer antipsychotics, such as Brexpiprazole and Cariprazine, are associated with relatively lower MetS risks in lipids, glucose, and body weight and may become candidates for a switching strategy for patients with MetS. However, there are only two published studies available that discuss switching to Brexpiprazole and none for Cariprazine. For patients with schizophrenia, switching to
Brepiprazole leads to a relatively low discontinuation rate of $17 \%$ at week $8 .{ }^{85}$ Different cross-titration periods, which ranged from one to four weeks, all showed comparable improvement in the PANSS total score compared to baseline. ${ }^{86}$ Nevertheless, none of these studies examined the effect of switching on metabolic parameters.

According to the existing research, switching to Aripiprazole, Amisulpride, Ziprasidone, or Lurasidone may become a feasible strategy for patients with schizophrenia comorbid with MetS, which may improve their metabolic parameters and continue to help their mental symptoms. However, the treatment discontinuation rate after switching remains relatively high, which may be related to the type of initial drug, the initial dose of the new drug, and the method of switching. Therefore, it is necessary to comprehensively evaluate the patient's disease characteristics and previous medications prior to switching, to pay attention to individual differences, and to select drugs in a targeted manner. In addition, most of the current studies utilized an open-label design with small sample sizes, various dosages of medications, and different switching modes. The lack of systematic review and metaanalyses also limits the promotion and application of these results. Furthermore, newer antipsychotics, including Lurasidone, Brexpiprazole, and Cariprazine are still relatively understudied and further studies examining the effect of these newer antipsychotics on metabolic parameters are needed. Their relatively high treatment cost may also limit their use. To minimize the risk of withdrawal symptoms, relapse, or recurrence, it is important to choose a suitable switching method. ${ }^{87,88}$ Abrupt discontinuation, specifically referring to the use of the second antipsychotic on the second day immediately following the discontinuation of the original antipsychotic, should be avoided as much as possible in clinical practice; crosstapering may be a safer choice. ${ }^{68}$ Although it is the simplest strategy, abrupt discontinuation involves high risks related to withdrawals and drug interaction. ${ }^{68}$ Cross-tapering refers to the gradual decrease of the first antipsychotic while gradually increasing the second antipsychotic to the appropriate therapeutic dose. This is the most commonly used switching method in clinical practice. During the overlap period of cross-tapering, both the risk of resurgence and the risk of adverse drug reactions can be minimized. ${ }^{68}$ In the above switching studies, the crosstapering method is frequently adopted.

There are also studies comparing the safety and efficacy of various switching methods when switching to 
aripiprazole. $^{76}$ The switching methods compared include abrupt discontinuation (discontinuation of the original drug and direct addition of Aripiprazole to $30 \mathrm{mg}$ per day), gradual reduction (the direct addition of Aripiprazole at $30 \mathrm{mg}$ per day and then a gradual discontinuation of the original drug within two weeks), and cross-tapering (Aripiprazole titrated to $30 \mathrm{mg}$ within three weeks while the original drug was stopped within two weeks). The results of the eight-week follow-up demonstrate that the body weight, PANSS total scores, and positive and negative symptom scores of the three groups improve, but with no statistical difference among the groups. However, another study comparing different switching strategies suggested that, although the long-term safety and efficacy outcomes of different strategies were equivalent, the abrupt discontinuation group suffered from a higher risk of early symptoms worsening compared with the cross-tapering group. ${ }^{89}$ In conclusion, when choosing switching methods, drug factors such as the half-life of the original drug and the drug to be switched, common adverse effects, and possible drug interactions should all be considered. ${ }^{68}$ Currently, however, it is believed that cross-tapering is still the most reliable method based on published studies and clinical practice and should be considered best practice.

A recent study also compared the metabolic effects of switching to antipsychotics with lower metabolic risks and combining them with metformin. ${ }^{90}$ The initial drug was either switched to Aripiprazole or added with metformin, with a follow-up of 24 weeks. The BMI of the two groups decreased significantly. In the combination group, the fasting blood glucose significantly improved, insulin decreased, and blood lipids remained unchanged, while in the Aripiprazole group the blood glucose moderately improved. Additionally, the BPRS scores of all groups improved, with no difference among the groups, suggesting equal improvement of psychotic symptoms. The safety profiles were good, but the gastrointestinal reaction of patients in the combination group was more obvious.

\section{Conclusion}

In summary, patients with schizophrenia often have metabolic abnormalities or MetS, which can seriously affect the disease prognosis and quality of life. Use of SGAs is an important risk factor of MetS, particularly in those who have a higher antagonism profile of 5-HT2C, H1, and M3 receptors. Among the widely used SGAs, Clozapine and Olanzapine are most likely to cause MetS, while the metabolic risk of Ziprasidone, Aripiprazole, Amisulpride, and newer antipsychotics like Lurasidone, Brexpiprazole, and Cariprazine are relatively low.

According to the few current studies, switching to an antipsychotic with a low metabolic risk, such as Amisulpride, Aripiprazole, Lurasidone, or Ziprasidone may improve the metabolic parameters of patients with schizophrenia without the deterioration of psychotic symptoms and with negligible side effects and a satisfactory safety profile. Therefore, a switching strategy may be an optimal choice for patients with schizophrenia comorbid with MetS or metabolic abnormalities. However, the reliability of the current studies is affected by factors such as open-label designs, different therapeutic doses, and high interruption rates. ${ }^{53}$ Future systematic reviews and metaanalyses are in need to provide additional evidence-based support to develop safer, more effective, and more optimized treatment and management strategies for patients with schizophrenia with MetS.

Besides, combination therapies of antipsychotics with mood stabilizers, or antidepressants, or electroconvulsive therapy (ECT) are widely used in clinical practice, especially among patients with schizophrenia who do not respond sufficiently. ${ }^{46,91-93}$ To avoid MetS risk caused by combination, selection of lower MetS risk options like bupropion and ECT should be considered. Future research specifically on minimization of MetS risk of combination therapy among patients with schizophrenia is needed.

\section{Acknowledgments}

The current work was supported by National Key R\&D program of China (grant No. 2017YFC1311103). The medical department of Sanofi China offered scientific and medical informational support of this work, with Sanofi helping provide the most current product information with all mentioned products, although they did not propose any specific therapy and therefore did not giving any specific treatment recommendations.

\section{Disclosure}

Hui Ye is an employee of Sanofi. The authors report no other potential conflicts of interest in this work.

\section{References}

1. Bosia M, Pigoni A, Cavallaro R. Genomics and epigenomics in novel schizophrenia drug discovery: translating animal models to clinical research and back. Expert Opin Drug Discov. 2015;10(2):125-139. doi: $10.1517 / 17460441.2015 .976552$ 
2. The IDF consensus worldwide definition of the metabolic syndrome. Available from: http://www.idf.org/webdata/docs/IDF_ Metasyndrome_definition.pdf. Accessed November 24, 2020.

3. Malhotra N, Grover S, Chakrabarti S, Kulhara P. Metabolic syndrome in schizophrenia. Indian $J$ Psychol Med. 2013;35(3):227-240. doi:10.4103/0253-7176.119471

4. Diabetes Branch of Chinese Medical Association. Guidelines for prevention and treatment of type 2 diabetes in China (2017 edition). Chin J Pract Int Med. 2018;38(4):292-344. doi:10.19538/j.nk2018 040108

5. De Hert M, Schreurs V, Vancampfort D, Van Winkel R. Metabolic syndrome in people with schizophrenia: a review. World Psychiatry. 2009;8(1):15-22. doi:10.1002/j.2051-5545.2009.tb00199.x

6. De Hert MA, van Winkel R, Van Eyck D, et al. Prevalence of the metabolic syndrome in patients with schizophrenia treated with antipsychotic medication. Schizophr Res. 2006;83(1):87-93. doi:10.101 6/j.schres.2005.12.855

7. De Hert M, van Winkel R, Van Eyck D, et al. Prevalence of diabetes, metabolic syndrome and metabolic abnormalities in schizophrenia over the course of the illness: a cross-sectional study. Clin Pract Epidemiol Ment Health. 2006;2:14. doi:10.1186/1745-0179-2-14

8. Mitchell AJ, Vancampfort D, Sweers K, van Winkel R, Yu W, De Hert M. Prevalence of metabolic syndrome and metabolic abnormalities in schizophrenia and related disorders-a systematic review and meta-analysis. Schizophr Bull. 2013;39(2):306-318. doi:10.1093/ schbul/sbr148

9. Vancampfort D, Stubbs B, Mitchell AJ, et al. Risk of metabolic syndrome and its components in people with schizophrenia and related psychotic disorders, bipolar disorder and major depressive disorder: a systematic review and meta-analysis. World Psychiatry. 2015;14(3):339-347. doi:10.1002/wps.20252

10. Lee JS, Kwon JS, Kim D, et al. Prevalence of metabolic syndrome in patients with schizophrenia in Korea: a Multicenter Nationwide Cross-Sectional Study. Psychiatry Investig. 2017;14(1):44-50. doi:10.4306/pi.2017.14.1.44

11. Schorr SG, Slooff CJ, Bruggeman R, Taxis K. The incidence of metabolic syndrome and its reversal in a cohort of schizophrenic patients followed for one year. J Psychiatr Res. 2009;43(13):11061111. doi:10.1016/j.jpsychires.2009.03.002

12. McEvoy JP, Meyer JM, Goff DC, et al. Prevalence of the metabolic syndrome in patients with schizophrenia: baseline results from the Clinical Antipsychotic Trials of Intervention Effectiveness (CATIE) schizophrenia trial and comparison with national estimates from NHANES III. Schizophr Res. 2005;80(1):19-32. doi:10.1016/j. schres.2005.07.014

13. Sugawara N, Yasui-Furukori N, Sato Y, et al. Prevalence of metabolic syndrome among patients with schizophrenia in Japan. Schizophr Res. 2010;123(2-3):244-250. doi:10.1016/j.schres.2010.08.030

14. Srisurapanont M, Likhitsathian S, Boonyanaruthee V, Charnsilp C, Jarusuraisin N. Metabolic syndrome in Thai schizophrenic patients: a naturalistic one-year follow-up study. BMC Psychiatry. 2007;7:14. doi:10.1186/1471-244X-7-14

15. Wenlong S, Chenhu L, Shunzeng R, Guilai Z, Hong Z. Investigation on the prevalence of metabolic syndrome in patients with schizophrenia. Neurol Dis Mental Health. 2007;7(6):431-433. doi:10.3969/ j.issn.1009-6574.2007.06.007

16. Dehua Y, Lihua L, Yong F, Yuxia D. Investigation of schizophrenia patients with metabolic syndrome. J Clin Psychiatry. 2011;21 (5):326-328.

17. Jie Y, Haijun L, Yazhong L, Jianhua M, Zhimeng L. The prevalence of metabolic syndrome and related factors in patients with schizophrenia. Chin J Health Psychol. 2012;20(6):808-809.

18. Jiqun X, Weilu Y, Shaowei O, Yuanhui Z, Zhibin Z. Investigation and analysis of the incidence of metabolic syndrome and related risk factors in outpatients with schizophrenia. China Contemp Med. 2018;25(24):56-58. doi:10.3969/j.issn.1674-4721.2018.24.016
19. Yan L, Huafang L, Yumei J, Peiqing W, Zhushu Q. The prevalence and related factors of metabolic syndrome in hospitalized patients with schizophrenia. Shanghai Psychiatry. 2009;21(1):16-19. doi:10. 3969/j.issn.1002-0829.2009.01.004

20. Mottillo S, Filion KB, Genest J, et al. The metabolic syndrome and cardiovascular risk a systematic review and meta-analysis. $\mathrm{J} \mathrm{Am} \mathrm{Coll}$ Cardiol. 2010;56(14):1113-1132. doi:10.1016/j.jacc.2010.05.034

21. Kritharides L, Chow V, Lambert TJ. Cardiovascular disease in patients with schizophrenia. Med J Aust. 2017;206(2):91-95. doi:10. 5694/mja16.00650

22. Hayes JF, Marston L, Walters K, King MB, Osborn D. Mortality gap for people with bipolar disorder and schizophrenia: UK-based cohort study 2000-2014. Br J Psychiatry. 2017;211(3):175-181. doi:10.11 92/bjp.bp.117.202606

23. Arango C, Bobes J, Aranda P, Carmena R, Garcia-Garcia M, Rejas J. A comparison of schizophrenia outpatients treated with antipsychotics with and without metabolic syndrome: findings from the CLAMORS study. Schizophr Res. 2008;104(1-3):1-12. doi:10.10 16/j.schres.2008.05.009

24. Dibonaventura M, Gabriel S, Dupclay L, Gupta S, Kim E. A patient perspective of the impact of medication side effects on adherence: results of a cross-sectional nationwide survey of patients with schizophrenia. BMC Psychiatry. 2012;12:20. doi:10.1186/1471-244X-12-20

25. Godin O, Leboyer M, Schurhoff F, et al. Metabolic syndrome and illness severity predict relapse at 1-year follow-up in schizophrenia: the FACE-SZ cohort. J Clin Psychiatry. 2018;79:6. doi:10.4088/ JCP. $17 \mathrm{~m} 12007$

26. Bora E, Akdede BB, Alptekin K. The relationship between cognitive impairment in schizophrenia and metabolic syndrome: a systematic review and meta-analysis. Psychol Med. 2017;47(6):1030-1040. doi:10.1017/S0033291716003366

27. Scigliano G, Ronchetti G. Antipsychotic-induced metabolic and cardiovascular side effects in schizophrenia: a novel mechanistic hypothesis. CNS Drugs. 2013;27(4):249-257. doi:10.1007/s40263013-0054-1

28. Ryan MC, Collins P, Thakore JH. Impaired fasting glucose tolerance in first-episode, drug-naive patients with schizophrenia. Am J Psychiatry. 2003;160(2):284-289. doi:10.1176/appi.ajp.160. 2.284

29. Cordes J, Bechdolf A, Engelke C, et al. Prevalence of metabolic syndrome in female and male patients at risk of psychosis. Schizophr Res. 2017;181:38-42. doi:10.1016/j.schres.2016.09.012

30. Ellingrod VL, Taylor SF, Dalack G, et al. Risk factors associated with metabolic syndrome in bipolar and schizophrenia subjects treated with antipsychotics: the role of folate pharmacogenetics. J Clin Psychopharmacol. 2012;32(2):261-265. doi:10.1097/JCP.0b013e318 2485888

31. Cheng C, Chiu HJ, Loh E, et al. Association of the ADRA1A gene and the severity of metabolic abnormalities in patients with schizophrenia. Prog Neuropsychopharmacol Biol Psychiatry. 2012;36 (1):205-210. doi:10.1016/j.pnpbp.2011.10.011

32. Henderson DC, Vincenzi B, Andrea NV, Ulloa M, Copeland PM. Pathophysiological mechanisms of increased cardiometabolic risk in people with schizophrenia and other severe mental illnesses. Lancet Psychiatry. 2015;2(5):452-464. doi:10.1016/S2215-0366 (15)00115-7

33. Ventriglio A, Gentile A, Stella E, Bellomo A. Metabolic issues in patients affected by schizophrenia: clinical characteristics and medical management. Front Neurosci. 2015;9:297. doi:10.3389/fnins.2015. 00297

34. Tianmei S, Yan L. The risk of metabolic syndrome in patients with schizophrenia. J Psychiatry. 2009;22(1):66-69. doi:10.3969/j.issn. 1009-7201.2009.01.028

35. Khan AY, Zaidi DSN. Reducing morbidity and mortality from common medical conditions in schizophrenia. Curr Psychiatr. 2016;30-2 (34-8):40. 
36. Stahl SM. Stahl's Essential Psychopharmacology: Neuroscientific Basis and Practical Applications (4th Edition). Cambridge: Cambridge University Press; 2013.

37. Reynolds GP, Kirk SL. Metabolic side effects of antipsychotic drug treatment-pharmacological mechanisms. Pharmacol Ther. 2010;125 (1):169-179. doi:10.1016/j.pharmthera.2009.10.010

38. Aringhieri S, Carli M, Kolachalam S, et al. Molecular targets of atypical antipsychotics: from mechanism of action to clinical differences Pharmacol Ther. 2018;192:20-41. doi:10.1016/j.pharmthera.2018.06.012

39. Matsui-Sakata A, Ohtani H, Sawada Y. Receptor occupancy-based analysis of the contributions of various receptors to antipsychoticsinduced weight gain and diabetes mellitus. Drug Metab Pharmacokinet. 2005;20(5):368-378. doi:10.2133/dmpk.20.368

40. Montastruc F, Palmaro A, Bagheri H, Schmitt L, Montastruc JL, LapeyreMestre M. Role of serotonin 5-HT2C and histamine H1 receptors in antipsychotic-induced diabetes: a pharmacoepidemiological-pharmacodynamic study in VigiBase. Eur Neuropsychopharmacol. 2015;25 (10):1556-1565. doi:10.1016/j.euroneuro.2015.07.010

41. Correll CU, Lencz T, Malhotra AK. Antipsychotic drugs and obesity. Trends Mol Med. 2011;17(2):97-107. doi:10.1016/j.molmed.2010.10.010

42. Galletly C, Castle D, Dark F, et al. Royal Australian and New Zealand college of psychiatrists clinical practice guidelines for the management of schizophrenia and related disorders. Aust $N \mathrm{Z} \mathrm{J}$ Psychiatry. 2016;50(5):410-472. doi:10.1177/0004867416641195

43. Hasan A, Falkai P, Wobrock T, et al. World Federation of Societies of Biological Psychiatry (WFSBP) guidelines for biological treatment of schizophrenia - a short version for primary care. Int J Psychiatry Clin Pract. 2017;21(2):82-90. doi:10.1080/13651501.2017.1291839

44. Jingping Z, Shenxun S. Guidelines for the Prevention and Treatment of Schizophrenia in China (Second Edition). Beijing: China Medical Electronic Audiovisual Publishing House; 2015.

45. Dols A, Sienaert $P$, van Gerven $H$, et al. The prevalence and management of side effects of lithium and anticonvulsants as mood stabilizers in bipolar disorder from a clinical perspective: a review. Int Clin Psychopharmacol. 2013;28(6):287-296. doi:10.1097/YIC.0b013e32836435e2

46. Ng QX, Chong J, Chee KT. Add-on pharmacotherapy for patients with first-episode schizophrenia: a clinical perspective. Eur J Clin Pharmacol. 2020. doi:10.1007/s00228-020-02973-2

47. Delacretaz A, Vandenberghe F, Gholam-Rezaee M, et al. Early changes of blood lipid levels during psychotropic drug treatment as predictors of long-term lipid changes and of new onset dyslipidemia. J Clin Lipidol. 2018;12(1):219-229. doi:10.1016/j.jacl.20 17.10.002

48. Vandenberghe F, Najar-Giroud A, Holzer L, Conus P, Eap CB, Ambresin AE. Second-generation antipsychotics in adolescent psychiatric patients: metabolic effects and impact of an early weight change to predict longer term weight gain. J Child Adolesc Psychopharmacol. 2018;28(4):258-265. doi:10.1089/cap.2017. 0038

49. Speyer H, Jakobsen AS, Westergaard C, et al. Lifestyle interventions for weight management in people with serious mental illness: a systematic review with meta-analysis, trial sequential analysis, and meta-regression analysis exploring the mediators and moderators of treatment effects. Psychother Psychosom. 2019;88(6):350-362. doi:10.1159/000502293

50. Speyer H, Christian BNH, Birk M, et al. The CHANGE trial: no superiority of lifestyle coaching plus care coordination plus treatment as usual compared to treatment as usual alone in reducing risk of cardiovascular disease in adults with schizophrenia spectrum disorders and abdominal obesity. World Psychiatry. 2016;15(2):155-165. doi:10.1002/wps. 20318

51. Curtis J, Watkins A, Rosenbaum S, et al. Evaluating an individualized lifestyle and life skills intervention to prevent antipsychoticinduced weight gain in first-episode psychosis. Early Interv Psychiatry. 2016;10(3):267-276. doi:10.1111/eip.12230
52. Firth J, Marx W, Dash S, et al. The effects of dietary improvement on symptoms of depression and anxiety: a meta-analysis of randomized controlled trials. Psychosom Med. 2019;81(3):265-280. doi:10.1097/ PSY.0000000000000673

53. Marteene W, Winckel K, Hollingworth S, et al. Strategies to counter antipsychotic-associated weight gain in patients with schizophrenia. Expert Opin Drug Saf. 2019;18(12):1149-1160. doi:10.1080/147403 38.2019.1674809

54. Mizuno Y, Suzuki T, Nakagawa A, et al. Pharmacological strategies to counteract antipsychotic-induced weight gain and metabolic adverse effects in schizophrenia: a systematic review and meta-analysis. Schizophr Bull. 2014;40(6):1385-1403. doi:10.1093/schbul/ sbu030

55. Wu RR, Zhao JP, Jin H, et al. Lifestyle intervention and metformin for treatment of antipsychotic-induced weight gain: a randomized controlled trial. JAMA. 2008;299(2):185-193. doi:10.1001/jama.20 07.56-b

56. Fan X, Borba CP, Copeland P, et al. Metabolic effects of adjunctive aripiprazole in clozapine-treated patients with schizophrenia. Acta Psychiatr Scand. 2013;127(3):217-226. doi:10.1111/acps.12009

57. Deberdt W, Winokur A, Cavazzoni PA, et al. Amantadine for weight gain associated with olanzapine treatment. Eur Neuropsychopharmacol. 2005;15(1):13-21. doi:10.1016/j.euroneuro.2004.03.005

58. Ko YH, Joe SH, Jung IK, Kim SH. Topiramate as an adjuvant treatment with atypical antipsychotics in schizophrenic patients experiencing weight gain. Clin Neuropharmacol. 2005;28(4):169175. doi:10.1097/01.wnf.0000172994.56028.c3

59. Rucker D, Padwal R, Li SK, Curioni C, Lau DC. Long term pharmacotherapy for obesity and overweight: updated meta-analysis. BMJ. 2007;335(7631):1194-1199. doi:10.1136/bmj.39385.413113.25

60. Romo-Nava F, Alvarez-Icaza GD, Fresan-Orellana A, et al. Melatonin attenuates antipsychotic metabolic effects: an eight-week randomized, double-blind, parallel-group, placebo-controlled clinical trial. Bipolar Disord. 2014;16(4):410-421. doi:10.1111/bdi.12196

61. Poyurovsky M, Fuchs C, Pashinian A, et al. Attenuating effect of reboxetine on appetite and weight gain in olanzapine-treated schizophrenia patients: a double-blind placebo-controlled study. Psychopharmacology (Berl). 2007;192(3):441-448. doi:10.1007/s00213-007-0731-1

62. Ghanizadeh A, Nikseresht MS, Sahraian A. The effect of zonisamide on antipsychotic-associated weight gain in patients with schizophrenia: a randomized, double-blind, placebo-controlled clinical trial. Schizophr Res. 2013;147(1):110-115. doi:10.1016/j.schres.2013.03.021

63. Jarskog LF, Hamer RM, Catellier DJ, et al. Metformin for weight loss and metabolic control in overweight outpatients with schizophrenia and schizoaffective disorder. Am J Psychiatry. 2013;170(9):10321040. doi:10.1176/appi.ajp.2013.12010127

64. Wu RR, Jin H, Gao K, et al. Metformin for treatment of antipsychoticinduced amenorrhea and weight gain in women with first-episode schizophrenia: a double-blind, randomized, placebo-controlled study. $\mathrm{Am} J$ Psychiatry. 2012;169(8):813-821. doi:10.1176/appi.ajp.2012.11091432

65. Carrizo E, Fernandez V, Connell L, et al. Extended release metformin for metabolic control assistance during prolonged clozapine administration: a 14 week, double-blind, parallel group, placebo-controlled study. Schizophr Res. 2009;113(1):19-26. doi:10.1016/j.schres.2009.05.007

66. Klein DJ, Cottingham EM, Sorter M, Barton BA, Morrison JA. A randomized, double-blind, placebo-controlled trial of metformin treatment of weight gain associated with initiation of atypical antipsychotic therapy in children and adolescents. Am J Psychiatry. 2006;163(12):2072-2079. doi:10.1176/ajp.2006.163.12.2072

67. Bouchoucha M, Uzzan B, Cohen R. Metformin and digestive disorders. Diabetes Metab. 2011;37(2):90-96. doi:10.1016/j.diabet.20 10.11.002

68. Keks N, Schwartz D, Hope J. Stopping and switching antipsychotic drugs. Aust Prescr. 2019;42(5):152-157. doi:10.18773/austprescr. 2019.052 
69. Lin CC, Bai YM, Wang YC, et al. Improved body weight and metabolic outcomes in overweight or obese psychiatric patients switched to amisulpride from other atypical antipsychotics. J Clin Psychopharmacol. 2009;29(6):529-536. doi:10.1097/JCP.0b013e31 $81 \mathrm{bf6} 13 \mathrm{e}$

70. Kim Y, Wang SM, Kwak KP, et al. Amisulpride switching in schizophrenic patients who showed suboptimal effect and/or tolerability to current antipsychotics in a naturalistic setting: an Explorative Study. Clin Psychopharmacol Neurosci. 2016;14(4):371-377. doi:10.9758/ cpn.2016.14.4.371

71. Linden M, Eich FX, Pyrkosch L. Do differences in atypical antipsychotics matter in routine practice? Medication switch from olanzapine and risperidone to amisulpride. Int Clin Psychopharmacol. 2007;22(3):175-178. doi:10.1097/YIC.0b013e3280148c19

72. Linden M, Scheel T, Eich FX. Improvement of patient compliance after switching from conventional neuroleptics to the atypical neuroleptic amisulpride. J Psychopharmacol. 2006;20(6):815-823. doi:10. 1177/0269881106061154

73. Stroup TS, McEvoy JP, Ring KD, et al. A randomized trial examining the effectiveness of switching from olanzapine, quetiapine, or risperidone to aripiprazole to reduce metabolic risk: comparison of antipsychotics for metabolic problems (CAMP). Am J Psychiatry. 2011;168(9):947-956. doi:10.1176/appi.ajp.2011.10111609

74. Newcomer JW, Campos JA, Marcus RN, et al. A multicenter, randomized, double-blind study of the effects of aripiprazole in overweight subjects with schizophrenia or schizoaffective disorder switched from olanzapine. J Clin Psychiatry. 2008;69(7):1046-1056. doi:10.4088/ jcp.v69n0702

75. Wani RA, Dar MA, Chandel RK, et al. Effects of switching from olanzapine to aripiprazole on the metabolic profiles of patients with schizophrenia and metabolic syndrome: a double-blind, randomized, open-label study. Neuropsychiatr Dis Treat. 2015;11:685-693. doi:10.2147/NDT.S80925

76. Casey DE, Carson WH, Saha AR, et al. Switching patients to aripiprazole from other antipsychotic agents: a multicenter randomized study. Psychopharmacology (Berl). 2003;166(4):391-399. doi:10.10 07/s00213-002-1344-3

77. Kim SW, Shin IS, Kim JM, et al. Effectiveness of switching to aripiprazole from atypical antipsychotics in patients with schizophrenia. Clin Neuropharmacol. 2009;32(5):243-249. doi:10.1097/WNF. 0b013e31819a68b5

78. Chen Y, Bobo WV, Watts K, Jayathilake K, Tang T, Meltzer HY. Comparative effectiveness of switching antipsychotic drug treatment to aripiprazole or ziprasidone for improving metabolic profile and atherogenic dyslipidemia: a 12-month, prospective, open-label study. $J$ Psychopharmacol. 2012;26(9):1201-1210. doi:10.1177/026988111143 0748

79. Mattingly GW, Haddad PM, Tocco M, et al. Switching to lurasidone following 12 months of treatment with risperidone: results of a 6month, open-label study. BMC Psychiatry. 2020;20(1):199. doi:10.11 86/s12888-020-02523-1

80. Deberdt W, Lipkovich I, Heinloth AN, et al. Double-blind, randomized trial comparing efficacy and safety of continuing olanzapine versus switching to quetiapine in overweight or obese patients with schizophrenia or schizoaffective disorder. Ther Clin Risk Manag. 2008;4(4):713-720. doi:10.2147/tcrm.s3153

81. Weiden PJ, Newcomer JW, Loebel AD, Yang R, Lebovitz HE. Longterm changes in weight and plasma lipids during maintenance treatment with ziprasidone. Neuropsychopharmacol. 2008;33(5):985-994. doi:10.1038/sj.npp.1301482
82. Wang HH, Cai M, Wang HN, et al. An assessor-blinded, randomized comparison of efficacy and tolerability of switching from olanzapine to ziprasidone and the combination of both in schizophrenia spectrum disorders. J Psychiatr Res. 2017;85:59-65. doi:10.1016/j.jpsychires. 2016.11.002

83. Alptekin K, Hafez J, Brook S, et al. Efficacy and tolerability of switching to ziprasidone from olanzapine, risperidone or haloperidol: an international, multicenter study. Int Clin Psychopharmacol. 2009;24(5):229-238. doi:10.1097/YIC.0b013e32832c2624

84. Li CH, Shi L, Zhan GL, Rao SZ, Zhang H. A twenty-four-week, open-label study on ziprasidone's efficacy and influence on glucolipid metabolism in patients with schizophrenia and metabolic disorder. Eur Rev Med Pharmacol Sci. 2013;17(16):2136-2140.

85. Ishigooka J, Usami T, Iwashita S, Kojima Y, Matsuo S. Post-hoc analysis investigating the safety and efficacy of brexpiprazole in Japanese patients with schizophrenia who were switched from other antipsychotics in a long-term study (secondary publication). Neuropsychopharmacol Rep. 2020;40(2):122-129. doi:10.1002/npr2. 12107

86. Correll CU, Shi L, Weiss C, et al. Successful switching of patients with acute schizophrenia from another antipsychotic to brexpiprazole: comparison of clinicians' choice of cross-titration schedules in a post hoc analysis of a randomized, double-blind, maintenance treatment study. CNS Spectr. 2019;24(5):507-517. doi:10.1017/S109 2852918001086

87. Burns T, Chabannes JP, Demyttenaere K. Switching antipsychotic medications: general recommendations and switching to amisulpride. Curr Med Res Opin. 2002;18(4):201-208. doi:10.1185/030079902 125000589

88. Weber M, Gutierrez AM, Mohammadi M. The risks and benefits of switching antipsychotics: a case study approach. Perspect Psychiatr Care. 2009;45(1):54-61. doi:10.1111/j.1744-6163.2009.00200.x

89. Pae CU, Serretti A, Chiesa A, et al. Immediate versus gradual suspension of previous treatments during switch to aripiprazole: results of a randomized, open label study. Eur Neuropsychopharmacol. 2009;19 (8):562-570. doi:10.1016/j.euroneuro.2009.04.002

90. Correll CU, Sikich L, Reeves G, et al. Metformin add-on vs. antipsychotic switch vs. continued antipsychotic treatment plus healthy lifestyle education in overweight or obese youth with severe mental illness: results from the IMPACT trial. World Psychiatry. 2020;19 (1):69-80. doi:10.1002/wps.20714

91. Josiassen RC, Joseph A, Kohegyi E, et al. Clozapine augmented with risperidone in the treatment of schizophrenia: a randomized, doubleblind, placebo-controlled trial. Am J Psychiatry. 2005;162(1):130136. doi:10.1176/appi.ajp.162.1.130

92. Sacks D, Baxter B, Campbell B, et al. Multisociety consensus quality improvement revised consensus statement for endovascular therapy of acute ischemic stroke. Int J Stroke. 2018;13(6):612-632. doi:10. 1177/1747493018778713

93. Sanghani SN, Petrides G, Kellner CH. Electroconvulsive therapy (ECT) in schizophrenia: a review of recent literature. Curr Opin Psychiatry. 2018;31(3):213-222. doi:10.1097/YCO.0000000000000 418 


\section{Publish your work in this journal}

Neuropsychiatric Disease and Treatment is an international, peerreviewed journal of clinical therapeutics and pharmacology focusing on concise rapid reporting of clinical or pre-clinical studies on a range of neuropsychiatric and neurological disorders. This journal is indexed on PubMed Central, the 'PsycINFO' database and CAS, and is the official journal of The International Neuropsychiatric Association (INA). The manuscript management system is completely online and includes a very quick and fair peer-review system, which is all easy to use. Visit http://www.dovepress.com/testimonials.php to read real quotes from published authors.

Submit your manuscript here: https://www.dovepress.com/neuropsychiatric-disease-and-treatment-journal 